\title{
Bauran Pemasaran Kacang Asin Merek Cendrawasih pada UD. Monang Denpasar-Bali
}

\author{
ARGADO SARAGIH, I.G.A.A. LIES ANGGRENI, \\ I DEWA AYU SRI YUDHARI
}

\author{
Program Studi Agribisnis, Fakultas Pertanian, Universitas Udayana \\ Jl. PB Sudirman Denpasar 80232 \\ Email: argadosaragih@gmail.com \\ liesanggreni@gmail.com
}

\begin{abstract}
The Marketing Mix of Salted Peanut of Cendrawasih Brand at UD. Monang Denpasar-Bali.
\end{abstract}

UD. Monang is an agro-industrial busines engaged in the production of snack of peanuts. Seeing the interest of consumers who tend to consume more salted peanuts than any other peanuts, this study aimed to determine the marketing mix conducted by UD. Monang on cendrawasih salted peanuts in term of the concept of product, price, place/distribution and promotion and to identify the constraints faced by UD. Monang in marketing salted peanuts produck with brand of cendrawasih. Based on the research result of cendrawasih salted peanuts produck are processed from raw materials of the best peanuts. The marketing mix carried out by UD. Monang on its produck was to provide three packaging in the form of plastic to make it look more appealing to consumers. Pricing implemented by UD. Monang is the cost plus pricing method which set the price based on the cost added by the percentage of the cost. For small-sized plastic packaging containing 125 gram was for Rp 3.900, 225 gram for Rp 8.400 and 350 gram for Rp 11.400. the company uses retailer as an intermediary in the distribution of products to the end consumers. Promotional activities used by the company was to use personal selling. Internal contrains faced was the company's performance in terms of the promotion was less effective. External constraints were that their competitors of similar products resulted in the company having to compete fairly tight.

Keywords: marketing mix, salted peanuts, personal selling, retailer

\section{Pendahuluan}

\subsection{Latar Belakang}

Sektor pertanian terkait dengan kegiatan ekonomi rakyat, baik dalam rangka menciptakan kesempatan kerja maupun kesempatan usaha dalam meningkatkan kesejahteraan (Hariyadi, dkk., 2000).Provinsi Bali, subsektor tanaman pangan sangat berkembang khususnya komoditi kacang yang merupakan bahan baku dalam industri olahan hasil pertanian. 
Provinsi Bali merupakan daerah tujuan wisata yang terkenal akan keindahan alam dan budayanya, dengan meningkatnya aktivitas dan arus wisatawan yang berkunjung untuk melihat keindahan alam dan menikmati kuliner khas Bali, secara tidak langsung berdampak pada tingkat perekonomian masyarakat Bali. Hal ini ditandai dengan munculnya perusahaan-perusahaan yang bergerak dibidang olahan hasil pertanian khususnya kacang yang dijadikan oleh-oleh khas bali seperti kacang tanah yang diolah menjadi kacang asin, kacang bawang, kacang disco, kacang kedelai dioalah menjadi susu kedelai dan kacang hijau diolah menjadi pia susu dan pia legong.

Salah satu perusahaan yang bergerak dibidang produksi dan pengolahan kacang adalah UD.Monang. UD. Monang adalah suatu usaha agroindustri yang bergerak dibidang produksi cemilan kacang-kacangan yang saat ini dikenal masyarakat sebagai oleh-oleh khas Bali. Usaha Kacang Asin Merek Cendrawasih ini yang terletak di Jalan Gunung Gede Kavling Persik No. 5 Denpasar-Bali yang memproduksi dan memasarkan Kacang Asin MerekCendrawasih tersebut. Melihat minat konsumen yang cenderung lebih banyak mengkonsumsi kacang asin dibanding jeniskacang yang lain untuk itu dalam penelitian ini ingin mengkaji tentang bagaimana bauran pemasaran Kacang Asin Merek Cendrawasih di UD. Monang Denpasar - Bali dengan melihat dari segi produk, harga, promosi dan tempat (distribusi) agar usaha yang dijalankan berkembang dan berkelanjutan dan mampu bersaing dengan perusahaan yang memiliki produk sejenis seperti kacang asin Rahayu, kacang asin Matahari, kacang asin Bali Jegeg.

\subsection{Tujuan Penelitian}

Penelitian ini bertujuan untuk mengetahui bauran pemasaran yang dilakukan oleh UD. Monang terhadap Kacang Asin Merek Cendrawasih ditinjau dari konsep produk, harga, tempat/distribusi dan promosi dan untuk mengetahui kendala-kendala yang dihadapi oleh UD. Monang dalam memasarkan produk kacang asin merek cendrawasih.

\section{Metode Penelitian}

\subsection{Lokasi dan Waktu Penelitian}

Penelitian ini dilakukan pada UD. Monang yang beralamat di Jalan Gunung Gede Kavling Persik No. 5 Denpasar-Bali. Penelitian dilaksanakan selama bulan November. Penentuan lokasi penelitian dipilih secara sengaja (purposive).

\subsection{Penentuan Informan Kunci}

Informan kunci adalah orang yang dimanfaatkan untuk memberikan informasi tentang situasi dan kondisi penelitian. Pengambilan informan kunci dilakukan dengan cara purposive yaitu tiga orang yang dipilih secara sengaja dengan pertimbangan bahwa informan merupakan pengelola perusahaan yang mengerti mengenai proses produksi pada UD. Monang serta dianggap memahami tentang 
kondisi perusahaan sehingga mampu memberikan informasi sesuai dengan tujuan penelitian. Peneliti memilih pemilik perusahaan sekaligus manager perusahan serta satu orang tenaga kerja yang menangani produksi dan satu orang tenaga kerja yang menangani bagian pemasaran.

\subsection{Metode Pengumpulan Data, Variabel Penelitian dan Metode Analisis Data}

Pengumpulan data dilakukan dengan cara observasi, wawancaradan studi dokumentasi. Variabel dalam penelitian ini mencakupbauran pemasaran (marketing mix) Kacang Asin Merek Cendrawasih, dan kendala- kendala yang dihadapi UD. Monang dalam bauran pemasaran (marketing mix). Metode analisis data yang digunakan dalam penelitian ini adalah metode analisis data yang digunakan dalam penelitian ini adalah metode analisis deskriptif kualitatif.

\section{Pembahasan}

\subsection{Bauran pemasaran}

Menurut Widiana (2010), bauran pemasaran merupakan seperangkat alat pemasaran yang digunakan perusahaan untuk mencapai tujuan perusahaan. Bauran pemasaran yang merupakan strategi yang dijalankan perusahaan yang berkaitan dengan penentuan bagaimana perusahaan menyajikan penawaran produk pada segmen pasar tertentu, yang merupakan sasaran pasarnya (Kotler, 1997).Proses bauran pemasaran yang dilakukan oleh UD. Monang menggunakan empat variabel antara lain (1) produk, (2) harga, (3) tempat/saluran distribusi, dan (4) promosi. Perusahaan memberikan tiga kemasan yaitu kemasan kecil (125 gram), kemasan sedang (225 gram), kemasan besar (350 gram) dengan harga berbeda-beda dalam setiap kemasan.

\subsection{Produk (product)}

Swastha dan Irawan (2003), Produk merupakan suatu sifat kompleks, baik dapat diraba maupun tidak diraba, termasuk bungkus, warna, harga, prestise perusahaan, pelayanan pengusaha dan pengecer, yang diterima pembeli untuk memuaskan keinginan dan kebutuhan. Menurut Kotler dan Armstrong(2001), Produk adalah segala sesuatu yang dapat ditawarkan kepasar untuk mendapatkan perhatian, dibeli, digunakan ataupun dikonsumsi. UD. Monang memproduksi berbagai macam produk kacang seperti kacang koro, kacang disco, kacang kapri, kacang balado dan kacang asin.

Bahan baku untuk pembuatan kacang asin diperoleh dari daerah Lombok dan Karangasem dengan harga berkisar antara $21.500 / \mathrm{kg}$ pada tahun 2015. Jumlah bahan baku yang diperlukan dalam sekali produksi adalah $100 \mathrm{~kg}$ dan perusahaan melakukan produksi kacang asin sebanyak dua kali dalam seminggu dengan jumlah bahan baku $100 \mathrm{~kg}$ per satu kali produksi. Berikut tabel jumlah produksi dan jumlah kemasan per satu kali produksi Kacang Asin Merek Cendrawasih di UD. Monang. 
Tabel 1.

Jumlah Produksi dan Jumlah Kemasan per Satu Kali Produksi

Kacang Asin Merek Cendrawasih di UD. Monang.

\begin{tabular}{lcc}
\hline \multicolumn{1}{c}{ Jenis Kemasan } & $\begin{array}{c}\text { Jumlah Produksi } \\
(\text { gram })\end{array}$ & $\begin{array}{c}\text { Jumlah Kemasan } \\
(\mathrm{pcs})\end{array}$ \\
\hline Kecil (125gram) & 30.000 & 240 \\
Sedang (225 gram) & 30.000 & 133 \\
Besar (350 gram) & 40.000 & 114 \\
\hline Total & 100.000 & 488 \\
\hline Sumber $:$ Data Sekunder UD.
\end{tabular}

Sumber : Data Sekunder UD.Monang (2015).

Dari tabel di atas dapat dilihat bahwa jumlah bahan baku yang di produksi untuk kemasan kecil (125 gr) sebanyak 30.000 gr yang menghasilkan 240 pcs, jumlah bahan baku yang di produksi untuk kemasan sedang (225 gr) sebanyak 30.000 gr yang menghasilkan 133 pcs, dan jumlah bahan baku yang di produksi untuk kemasan besar (350 gr) sebanyak 40.000 gr yang menghasilkan 114 pcs. Total keseluruhan kemasan per satu kali produksi sebanyak 488 pcs.

Pengolahan bahan baku dilakukan di pabrik UD. Monang yang terletak di jalan Gunung Gede Kapling Persik No. 5 Monang Maning. Proses pengolahan kacang asin di UD. Monang menggunakan alat dan bahan sebagai berikut:
a. Kacang Tanah.
b. Garam Dapur.
c. Air Bersih.
d. Panci atau ember.
e. Tampah atau keranjang bambu.
f. Mesin molen.
g. Kompor.
h. Pengaduk.
i. Kantong plastik.
j. Bawang putih.

Proses pembuatan atau pengolahan kacang asin terdiri dari beberapa tahap yang harus dilakukan yaitu mulai dari memilih bahan baku kacang tanah yang berkualitas hingga pengemasan. Berikut penjelasan secara lengkap tentang langkahlangkah pembuatan kacang asin di UD. Monang:

a. Memilih kacang tanah yang berkualitas.

Sortasi kacang tanah berdasarkan bentuk, warna, kecerahan dan besaran ukuran butir kacang. Alat yang digunakan untuk sortiran ini bisa memakai tangan (manual) atau ayakan.

b. Pembersihan dan penirisan.

Pembersihan kacang tanah dilakukan berkali-kali hingga benar-benar bersih agar tidak ditemukan kotoran yang menempel pada biji kacang. 
c. Perebusan.

Tujuan dari perebusan ini adalah untuk memperbesar pori-pori kacang tanah sehingga mempermudah proses pembumbuan.

d. Penjemuran.

Penjemuran dilakukan sekitar 6-8 jam tergantung kondisi cuaca.

e. Disangrai atau disangan.

Lama penyangraian selama 15 menit, tidak sampai matang namun mendekati matang.

f. Pengemasan.

Menurut Sudarmo (1999), bungkus atau kemasan produk merupakan atribut dalam pembeli mengambil keputusan untuk membeli suatu barang hanya karna kemasannya yang menarik. Pengemasan kacang Asin Merek Cendrawasih ini terdapat label yang dicantumkan label halal, komposisi dan keterangan izin usaha dengan slogan “ Lebih Gurih, Renyah dan Krezz !!!”.

\subsection{Harga (Price)}

Harga juga memposisikan nilai yang dimaksud perusahaan kepada pasar tentang produk dan mereknya. Penetapan harga merupakan suatu masalah jika perusahaan akan menetapkan harga untuk pertama kalinya atau ketika akan memperkenalkan produknya ke saluran distribusi baru (Kotler, 2005).Penetapan harga yang diterapkan oleh UD. Monang terhadap produk kacang asin Cendrawasih adalah dengan cara menambahkan marjin tetap kepada biaya dasar atau biaya pokok produk atau yang dikenal dengan penetapan harga berdasarkan biaya (cost plus pricing). Berikut contoh perhitungan biaya per satu kali produksi Kacang Asin Merek Cendrawasih di UD. Monang.

Tabel 2.

Perhitungan Biaya Per Satu Kali Produksi Kacang Asin Merek Cendrawasih di UD. Monang

\begin{tabular}{lccr}
\hline \multicolumn{1}{c}{ Daftar Biaya } & Jumlah & $\begin{array}{c}\text { Biaya/satuan } \\
(\mathrm{Rp})\end{array}$ & \multicolumn{1}{c}{$\begin{array}{c}\text { Total Biaya } \\
(\mathrm{Rp})\end{array}$} \\
\hline Bahan Baku (kg) & 100 & 21.500 & 2.150 .000 \\
\hline Tenaga Kerja (8 orang) & 8 & 12.000 & 96.000 \\
\hline Alat dan Bahan & 3 & & \\
Gas (tabung) & 2 & 19.000 & 57.000 \\
Garam (kg) & 2 & 6.000 & 12.000 \\
Bawang putih (kg) & 1 & 30.000 & 60.000 \\
Kemasan dan Pelabelan & & 200.000 & 200.000 \\
\hline Biaya operasional & 1 & & 40.000 \\
Listrik/air & 1 & 40.000 & 20.000 \\
Distribusi dan lain-lain & & & 2.635 .000 \\
\hline Total Biaya Keseluruhan & & &
\end{tabular}

Sumber : Data Primer (2015). 
Marjin tetap adalah keuntungan yang diperoleh perusahaan dimana besar keuntungan tersebut ditentukan sendiri oleh pihak perusahaan yaitu persen dari biaya dasar atau biaya produksi dari setiap kemasan produk kacang asin cendrawasih.Total biaya produksi yang dikeluarkan oleh UD. Monang dalam pembuatan kacang asin antara lain: biaya bahan baku, tenaga kerja, alat dan bahan dan biaya operasional yaitu sebesar Rp. 2.635.000,00.

Total biaya yang dikeluarkan UD. Monang per satu kali produksi dibagi menjadi biaya untuk setiap jenis kemasan karena jumlah bahan baku yang diproduksi pada jenis kemasan kecil dan kemasan sedang masing-masing sebesar 30\% dari jumlah bahan baku maka diasumsikan biaya produksi untuk kemasan kecil dan sedang yaitu masing-masing 30\% dari total biaya per satu kali produksi, yaitu sebesar Rp. 790.500,00 dan jumlah produksi kemasan besar sebesar 40\% dari jumlah bahan baku maka diasumsikan biaya produksi untuk kemasan besar yaitu $40 \%$ dari total biaya produksi, yaitu sebesar Rp. 1.054.000,00. Berikut tabel biaya produksi per jenis kemasan untuk satu kali produksi Kacang Asin Merek Cendrawasih di UD. Monang.

Tabel 3.

Biaya Produksi Per Jenis Kemasan untuk Satu Kali Produksi Kacang Asin Merek Cendrawasih di UD.Monang.

\begin{tabular}{lrr}
\hline Jenis kemasan & Total Biaya & Biaya Per Kemasan \\
\hline Kecil & 790.500 & 3.300 \\
Sedang & 790.500 & 6.000 \\
Besar & 1.054 .000 & 9.200 \\
\hline
\end{tabular}

Sumber : Data Primer (2015).

Berdasarkan total biaya produksi setiap jenis kemasan diperoleh biaya produksi per kemasan. Kemasan kecil biaya produksinya sebesar Rp. 3.300,00sedangkan untuk kemasan sedang biaya produksinya sebesar Rp. 6.000,00 dan untuk kemasan besar biaya produksinya sebesar Rp. 9.200,00 per kemasan, maka dapat diketahui besar keuntungan per kemasan untuk setiap jenis kemasan yaitu kemasan kecil memperoleh keuntungan sebesar Rp. 600,00 dari harga jual Rp. 3.900,00, kemasan sedang sebesar Rp. 4.200,00 dari harga jual Rp. 8.400,00, dan kemasan besar memperoleh keuntungan Rp. 2.200,00 dari harga jual Rp. 11.400,00. Berikut tabel keuntungan yang diperoleh per kemasan dari setiap jenis kemasan. 
Tabel 4.

Keuntungan yang Diperoleh Per Kemasan dari Setiap Jenis Kemasan Kacang Asin Merek Cendrawasih di UD. Monang

\begin{tabular}{lccc}
\hline \multicolumn{1}{c}{ Jenis Kemasan } & $\begin{array}{c}\text { Harga per Kemasan } \\
(\mathrm{Rp})\end{array}$ & $\begin{array}{c}\text { Keuntungan } \\
(\mathrm{Rp})\end{array}$ & $\begin{array}{c}\text { Persentase } \\
(\%)\end{array}$ \\
\hline Kecil & 3.900 & 600 & 18 \\
Sedang & 8.400 & 4.200 & 40 \\
Besar & 11.400 & 2.200 & 24 \\
\hline
\end{tabular}

Sumber : Data Primer (2015).

Berdasarkan keuntungan per kemasan dari setiap jenis kemasan maka diperoleh marjin tetap yaitu 18\% untuk kemasan kecil, $40 \%$ untuk kemasan sedang dan $24 \%$ untuk kemasan besar. Berdasarkan keuntungan per kemasan dapat diperoleh total keseluruhan keuntungan dalam satu kali produksi.

Tabel 5.

Total Keuntungan Per Satu Kali Produksi Kacang Asin Merek Cendrawasih di UD. Monang

\begin{tabular}{lccc}
\hline $\begin{array}{l}\text { Jenis } \\
\text { Kemasan }\end{array}$ & $\begin{array}{c}\text { Keuntungan } \\
(\mathrm{Rp})\end{array}$ & $\begin{array}{c}\text { Jumlah } \\
\text { Kemasan } \\
(\mathrm{Rp})\end{array}$ & $\begin{array}{c}\text { Total } \\
\text { Keuntungan } \\
(\mathrm{Rp})\end{array}$ \\
\hline Kecil & 600 & 240 & 144.000 \\
Sedang & 2.400 & 133 & 319.200 \\
Besar & 2.200 & 114 & 250.800 \\
\hline \multicolumn{2}{l}{ Total keuntungan Keseluruhan } & & 714.000 \\
\hline
\end{tabular}

Sumber : Data Primer (2015).

Berdasarkan tabel diatas total keuntungan setiap kemasan untuk satu kali produksi pada jenis Kacang Asin Merek Cendrawasih kemasan kecil, sedang, dan besar masing-masing yaitu sebesar Rp. 144.000,00, Rp. 319.200,00, dan Rp. 250.800,00. Sehingga total keuntungan secara keseluruhan sebesar Rp. 714.000,00 per satu kali produksi, sehingga total keuntungan dari penjualan kacang asin dalam sebulan yaitu sebesar Rp. 5.712.000,00.

Perusahaan menerapkan metode pembayaran dalam bentuk konsinyasi. Konsinyasi adalah penjualan dengan cara pemilik menitipkan barangnya kepada pihak lain untuk dijualkan dengan harga dan syarat yang telah di atur dalam perjanjian. Perjanjian konsinyasi berisi mengenai hak dan kewajiban antara kedua belah pihak.

\subsection{Distribusi (Place)}

Distribusi merupakan berbagai macam kegiatan yang dilakukan perusahaan untuk membuat produk menjadi lebih mudah diperoleh dan selalu tersedia untuk pelanggan sasaran. Distribusi juga dapat diartikan sebagai kegiatan pemasaran yang 
berusaha memperlancar penyampaian barang kepada konsumen.Angipora dalam Ratih (2009) menyatakan proses penyaluran produk sampai ketangan konsumen akhir dapat menggunakan saluran yang panjang atau pendek sesuai dengan kebijakan saluran distribusi yang ingin dilaksanakan perusahaan. Proses distribusi produk UD. Monang belum memiliki toko (outlet) sendiri sehingga perusahaan mendistribusikan Kacang Asin Merek Cendrawasihnya ke toko-toko, supermarket, pusat oleh-oleh khas Bali yang tersebar hampir diseluruh Kota Denpasar.

\subsection{Promosi (Promotion)}

Kegiatan promosi sangat berperan penting bagi perusahaan guna menarik konsumen. Promosi adalah unsur yang didayagunakan untuk memberitahukan dan membujuk pasar tentang produk baru perusahaan (Stanton, 1996).Kegiatan promosi yang dilakukan perusahaan adalah dalam bentuk personal selling. Penjualan personal (personal selling) merupakan komunikasi atau interaksi langsung antara penjualan dan calon pelanggan untuk memperkenalkan produk kepada calon pelanggan dan membentuk pemahaman pelanggan terhadap produk sehingga kemudian akan mencoba dan membelinya.

Saat ini UD. Monang melakukan promosi penjualan dengan melibatkan semua pihak perusahaan baik itu pemilik, manajer dan karyawannya. Promosi biasanya dilakukan dengan cara mendatangi toko-toko baru secara langsung untuk memperkenalkan dan menawarkan produk kacang cendrawasih sehingga retailer mau menjual produk Kacang Asin MerekCendrawasih kepada konsumen.

\subsection{Kendala-Kendala yang Dihadapi}

Segala usaha pasti memiliki kendala yang selalu menjadi hambatan untuk perkembangan usaha yang sedang dilakukan oleh perusahaan. Kendala tersebut harus bisa dipecahkan, apabila dibiarkan maka usaha tersebut tidak akan bertahan lama (bangkrut). Kendala tersebut apabila dapat terpecahkan maka usaha tersebut akan berkembang. Kendala yang dihadapi UD. Monang dalam pemasaran Kacang Asin Merek Cendrawasih, dalam penelitian ini dapat dilihat dari segi internal dan eksternal perusahaan sebagai berikut.

\subsubsection{Kendala internal}

Gitosudarmo (2000), menyatakan bahwa salah satu faktor yang menyebabkan kurang efektif yaitu pemilihan media yang kurang tepat. Kendala yang dihadapi oleh UD. Monang adalah kinerja perusahaan ditinjau dari segi promosi yang kurang efektif, karena kurangnya penyampaian informasi tentang produk kepada konsumen atau masyarakat. Perusahaan hanya menggunakan promosi melalui personal selling sehingga jangkauan informasi mengenai produk tidak dapat tersebar dengan luas. Informasi mengenai produk hanya dapat diketahui oleh retailer yang didatangi oleh perusahaan karenapihak retailerlah yang secara langsung berhubungan dengan konsumen. 


\subsubsection{Kendala eksternal}

Kendala eksternal yang dihadapi oleh UD. Monang dalam memasarkan produk Kacang Asin Merek Cendrawasih yaitu adanya pesaing produk sejenis seperti kacang asin Rajawali, kacang asin Rahayu, kacang asin Matahari, kacang asin Bali Jegeg dan lain sebagainya. Hal tersebut mengakibatkan perusahaan harus bersaing cukup ketat khususnya dari segi kualitas produk yang dihasilkan sehingga mempengaruhi harga dimana kacang asin cendrawasih dalam kemasan sedang (225 gram) dijual seharga Rp. 8.400,00 sedangkan kacang asin Rajawali yang merupakan pesaing menjual produknya seharga Rp. 13.000,00 dalam kemasan 250 gram. Perusahaan yang merupakan pesaing merupakan perusahaan yang cukup besar, yang memiliki merek atau brand yang lebih dulu dikenal oleh masyarakat.

\section{Simpulan dan Saran}

\subsection{Simpulan}

Berdasarkan hasil penelitian yang telah dijabarkan pada bab sebelumnya maka dapat disimpulkan beberapa hal sebagai berikut:

1. Penerapan bauran pemasaran pada UD. Monang adalah sebagai berikut :

a. Perusahaan menggunakan merek Cendrawasih pada produk yang dipasarkan dan perusahaan menawarkan tiga macam kemasan yaitu dalam bentuk kecil dengan ukuran 125 gram, sedang dengan ukuran 225 gram, dan besar dengan ukuran 350 gram.

b. Penetapan harga yang dilakukan oleh perusahaan dengan menggunakan metode penetapan harga berdasarkan biaya (cost plus pricing) dan Metode pembayaran yang digunakan perusahaan yaitu metode konsinyasi.

c. Perusahaan menggunakan tenaga retailer sebagai perantara dalam distribusi produk agar produk Kacang Asin Merek Cendrawasih sampai kepada konsumen akhir. Karena produk kacang asin merek cendrawasih masih tergolong baru sehingga perusahaan bekerja sama dengan pihak retailer.

d. Kegiatan promosi yang digunakan oleh perusahaan yaitu dengan menggunakan personal selling. Metode ini dianggap tepat sehingga pihak retailer mengetahui keunggulan produk dan dapat mempromosikan kembali produk Kacang Asin Merek Cendrawasih kepada konsumen.

2. Kendala-kendala yang dihadapi oleh UD. Monang terdiri atas kendala internal dan eksternal adalah sebagai berikut :

a. Kendala internal yang dihadapi oleh UD. Monang adalah kinerja perusahaan dalam segi promosi yang kurang efektif disebabkan karena kurangnya penyampaian informasi produk kepada masyarakat atau konsumen.

b. Kendala eksternal yang dihadapi UD. Monang adalah adanya pesaing produk sejenis. Hal ini menyebabkan perusahaan harus bersaing cukup ketat khususnya dari segi kualitas produk yang dihasilkan. 


\subsection{Saran}

Berdasarkan kesimpulan di atas maka dapat disarankan beberapa hal sebagai berikut.

1. Dalam menghadapi persaingan bisnis yang semakin ketat antara perusahaan kacang lainnya yang ada di Bali, perusahaan sebaiknya meninggkatkan mutu dan kualitas produk yang dipasarkan serta menemukan inovasi produk yang baru serta meningkatkan pelayanan terhadap konsumen.

2. UD. Monang perlu mempromosikan produknya melalui media sosial seperti radio, facebook, twiter, instagram dan lain lain. Disamping itu, UD. Monang juga harus membuat website sendiri agar lebih dikenal oleh masyarakat dalam melakukan pemesanan secara online.

\section{Ucapan Terima Kasih}

Penulis mengucapkan banyak terimakasih kepada semua pihak yang telah membantu dalam pelaksanaan penelitian ini, terutama kepada kedua orang tua yang telah memberikan bantuan baik moril maupun materil dalam penyusunan e-jurnal ini sehingga dapat selesai tepat pada waktunya.

\section{Daftar Pustaka}

Gitosudarmo, Indri, 2001. Manajemen Pemasaran, ANDI, Yogyakarta.

Hariyadi, P., Fauzi, M.A., Suhardiyanto, H. Pertanian : Motor Penggerak Pembangunan Nasional. Prosiding. Peranan Teknologi Pertanian Sebagai Faktor Dominan Untuk Memposisikan Pertanian Sebagai Common Platform Pembangunan Nasional. Fakultas Teknologi Pertanian Institut Pertanian Bogor. Internet. phariyadi.staff.ipb.ac.id/files/2012/12/Motor-PenggerakPertanian-Nasional.pdf. Diunduh tanggal 2 juli 2015.

Kotler, philip, 1997. Manajemen Pemasaran. Jilid 1. Edisi Ke-11 PT. Prenhallindo, Jakarta.

Kotler, Armstrong 2001. Manajemen Pemasaran. Gramedia, Jakarta.

Kotler, Philip, 2005. Manajemen Pemasaran, jilid 1 dan 2. Jakarta: PT. Indeks.

Ratih Kumala Dewi, Putu. 2009. Bauran Pemasaran Produk Olahan Stroberi di Strawberry Stop Restoran, Desa Candikuning, Kecamatan Baturiti, Kabupaten Tabanan. (skripsi) Fakultas Pertanian Universitas Udayana, Denpasar.

Stanton, William J.1996. Prinsip Pemasaran (terjemahan). Edisi 7,jilid1.Erlangga. Jakarta.

Sudarmo, G. 1999. Manajemen Pemasaran Edisi Pertama. FEPB. Yogyakarta.

Swastha, Basu dan Irawan. (2003). Manajemen Pemasaran Modern. (Edisi kedua). Yogyakarta :Liberty Offset.

Widiana, Muslichah E. dan Bonar Sinaga. (2010). Dasar-dasar Pemasaran. Bandung : Karya Putra Darwati. 